\section{Transmission of the Viruses of Trachoma, Inclusion Blennorrhœa and Lymphogranuloma to Mice}

MANY viruses of the psittacosis-lymphogranuloma group can be transmitted intracerebrally in mice. Recently, we have succeeded in passing some strains of the viruses of trachoma and inclusion blennorrhcea by this route. Most suitable for the purpose are 5 -week-old animals from a closed colony originating from the BSVS strain ${ }^{1}$. The passages were initiated with infected yolk sac. Cortisone $(0.5 \mathrm{mgm}$. subcutaneously daily, beginning $24 \mathrm{hr}$. before virus) did not apparently facilitate infection.

Four series of passages, at 5-7 day intervals, with the T'ang strain of trachoma, were all successful.

Definite symptoms of disease first developed after 3-4 passages, and are evident 3-4 days after infection. The fur becomes ruffled and the animals adopt a hunched posture and a stilted, trembling gait. The mice often scratch themselves excessively and may develop severe purulent conjunctivitis. Later the crania of the mice appear swollen due to cerebral oedema.

Neither elementary bodies nor inclusions have yet been detected in brain smears stained with GiemsaMay-Grïnwald, the iodine method of Smith, Gilkes and Sowa ${ }^{2}$ or by Castañeda's method. Preparations of infected brain made by differential centrifugation or by ether extraction do not appear to contain elementary bodies. However, virus can be readily detected by inoculating infected brain into the chick embryo yolk sac where it induces the formation of the characteristic elementary bodies. Mouse brain virus also induces the formation of inclusion bodies in cell cultures (unpublished observations).

Material from the seventeenth passage produced no reaction when injected intracerebrally into a macaque monkey, or when rubbed on to the lightly abraded conjunctiva of the upper lid of a second monkey.

On a number of occasions, infected brains have been titrated by the intracerebral method in mice and chick embryos. By either method the usual titre is of the order of $10^{4} I D 50 / \mathrm{ml}$.

Suckling mice inoculated with this strain of virus show little sign of infection until 10-14 days later. When titrated in suckling mice the apparent titre of the preparation used was $10^{2} I D 50 / \mathrm{ml}$. after one week, as judged by the proportion of mice showing symptoms at that time. One week later the apparent titre had risen to $10^{3 \cdot 8} I D 50 / \mathrm{ml}$.

A boiled ether-acetone extracted mouse brain antigen was prepared by Casals's ${ }^{3}$ method. This fixed complement in the presence of serum from a patient with lymphogranuloma diluted to 1 in 128 , thus demonstrating the presence of the lymphogranulomapsittacosis group antigen.

At each virus passage normal mouse brain was passed in series as a control. None of the control animals showed evidence of infection, thus eliminating the possibility of latent infection with other viruses of the psittacosis-lymphogranuloma group.

Material from each passage was seeded on to 5 per cent horse blood agar plates and into Brewer's thioglycollate medium. An occasional bacterial contaminant was encountered, but in the great majority of instances no bacterial growth occurred.

Three attempts to carry the brain-adapted virus intraperitoneally in mice were unsuccessful, whether cortisone was given or not. In one series virus was recovered from the spleen after 3 but not after 6 passages at 7-day intervals. In two series virus was recovered only on the first passage. No symptoms of disease developed.

Three series of intracerebral passages with the $G 1$ strain of trachoma virus, with and without cortisone. and two series with the $G 17$ strain were all negative and virus could not be re-isolated after from 2 to 4 serial passages.

Two series of intracerebral passages with the $L B 2$ strain of inclusion blennorrhœea appeared to be succeeding at the first passage, and virus was recovered in the yolk sac. At subsequent passages, the initia] mild symptoms of infection failed to be reproduced and passage into eggs was negative.

By contrast, a series of passages with the $L B 1$ strain of inclusion blennorrhœea has been carried successfully through 13 serial transfers, with recovery of the virus in the yolk sac at intervals up to the twelfth passage. The yolk sac virus used to initiate infection was more toxic than was the T'ang virus and dilutions to $10^{-2}$ killed the majority of the recipients within 2-3 days. After intracerebral injection of dilutions of $10^{-3}$ or $10^{-4}$, symptoms of disease appeared on the seventh day at the first passage. They did not differ from those described above.

As far as the mouse is concerned, therefore, the behaviour of some strains of trachoma and inclusion blennorrhœa is very similar to that of the Iymphogranuloma virus. Through the courtesy of Prof. C. Barwell, we obtained 2 strains of this virus, one the $J . H$. strain long-adapted to the yolk sac, and the other (Ross) a strain recently isolated from man. On intracerebral passage in mice both behaved similarly to the T'ang virus, and after 3-4 passages produced symptoms indistinguishable from those described above. (It should be added that the viruses used in this investigation have, throughout, been handled in different isolation units, and the various series of transfers have been carried out by different personnel.) Attempts to carry these lymphogranuloma viruses serially by intraperitoneal inoculation of mice failed.

Imperial Chemical Industries, Ltd.,

Pharmaceuticals Division,

Alderley Park, Macclesfield. P. Reeve

Medical Research Council

Trachoma Research Group,

The Lister Institute of Preventive Medicine, Chelsea Bridge Road, London, S.W.1.

${ }^{1}$ Webster, L. T., J. Exp. Med., 65, 261 (1937).

${ }^{2}$ Gilkes, M. J., Smith, C. H., and Sowa, J., Brit. J. Ophthal., 42, 473 (1958). ${ }^{3}$ Casals, J., Olitsky, P. K., and Anslow, R. O., J. Exp. Med., 94, 123

\section{STATISTICS}

\section{Earthquakes and Uranus: Misuse of a Statistical Test of Significance}

There are always a large number of persons engaged in searching for correlations between pairs of variables, most of which are, in fact, uncorrelated. From the way in which statistical tests of significance are constructed, we know that in the cases in which no correlation exists the search will be spuriously rewarded, on the average once in every hundred 